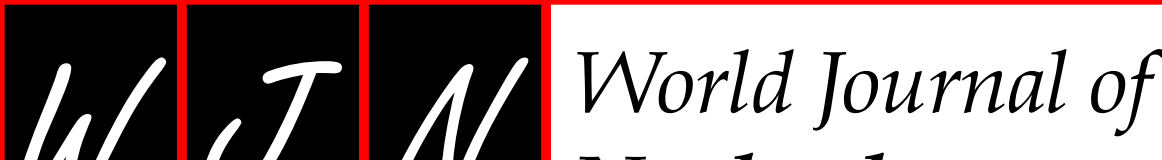 Nephrology
}

Submit a Manuscript: http:/ / www.wjgnet.com/esps/ Help Desk: http:/ /www.wjgnet.com/esps/helpdesk.aspx DOI: $10.5527 /$ wjn.v5.i6.547
World J Nephrol 2016 November 6; 5(6): 547-550

ISSN 2220-6124 (online)

(C) 2016 Baishideng Publishing Group Inc. All rights reserved.

\section{Antineutrophil cytoplasmic antibodies crescentic allograft glomerulonephritis after sofosbuvir therapy}

\author{
Shilpa Gadde, Belinda Lee, Laura Kidd, Rubin Zhang
}

Shilpa Gadde, Belinda Lee, Laura Kidd, Rubin Zhang, Department of Nephrology and Hypertension, Tulane University School of Medicine, New Orleans, LA 70112, United States

Author contributions: Gadde S, Lee B and Kidd L contributed to the acquisition of data and writing; Zhang R contributed to the writing and revision of this manuscript.

Institutional review board statement: This case report was exempt from the Institutional Review Board standards at Tulane University School of Medicine in New Orleans.

Informed consent statement: The patient involved in this study gave his written informed consent authorizing use and disclosure of his protected health information.

Conflict-of-interest statement: All the authors have no conflicts of interests to declare.

Open-Access: This article is an open-access article which was selected by an in-house editor and fully peer-reviewed by external reviewers. It is distributed in accordance with the Creative Commons Attribution Non Commercial (CC BY-NC 4.0) license, which permits others to distribute, remix, adapt, build upon this work non-commercially, and license their derivative works on different terms, provided the original work is properly cited and the use is non-commercial. See: http://creativecommons.org/ licenses/by-nc/4.0/

\section{Manuscript source: Invited manuscript}

Correspondence to: Rubin Zhang, MD, FASN, Professor of Medicine, Department of Nephrology and Hypertension, Tulane University School of Medicine, 1430 Tulane Ave, New Orleans, LA 70112, United States. rzhang@tulane.edu

Telephone: +1-504-9881457

Fax: +1-504-9887510

Received: June 15, 2016

Peer-review started: June 21, 2016

First decision: July 27, 2016

Revised: August 5, 2016

Accepted: October 5, 2016

Article in press: October 9, 2016

Published online: November 6, 2016

\begin{abstract}
Antineutrophil cytoplasmic antibodies (ANCA) are well known to be associated with several types of vasculitis, including pauci-immune crescentic glomerulonephritis, a form of rapid progressive glomerular nephritis (RPGN). ANCA vasculitis has also been reported after administration of propylthiouracil, hydralazine, cocaine (adulterated with levimasole), allopurinol, penicillamine and few other drugs. All previously reported cases of drug-associated ANCA glomerulonephritis were in native kidneys. Sofosbuvir is a new and effective drug for hepatitis $C$ virus infection. Here, we report a case of ANCA vasculitis and RPGN following sofosbuvir administration in a kidney transplant recipient. It also represents the first case of drug-associated ANCA vasculitis in a transplanted kidney. Further drug monitoring is necessary to elucidate the degree of association and possible causal effect of sofosbuvir and perinuclear ANCA vasculitis.
\end{abstract}

Key words: Crescentic glomerulonephritis; Vasculitis; Antineutrophil cytoplasmic antibody; Sofosbuvir; Kidney transplant

(c) The Author(s) 2016. Published by Baishideng Publishing Group Inc. All rights reserved.

Core tip: Antineutrophil cytoplasmic antibodies (ANCA) vasculitis is well known to be associated with several drugs, including propylthiouracil, hydralazine, cocaine, levimasole and others. All previous cases of drugassociated ANCA glomerulonephritis were in native kidneys. Here, we report a case of ANCA vasculitis following sofosbuvir administration in a kidney transplant recipient. It is also the first case of drug-associated ANCA vasculitis in a transplanted kidney. Further drug monitoring is necessary to elucidate the degree of association and possible causal effect of sofosbuvir and perinuclear ANCA vasculitis.

Gadde B, Lee B, Kidd L, Zhang R. Antineutrophil cytoplasmic 
antibodies crescentic allograft glomerulonephritis after sofosbuvir therapy. World J Nephrol 2016; 5(6): 547-550 Available from: URL: http://www.wjgnet.com/2220-6124/full/v5/i6/547.htm DOI: http://dx.doi.org/10.5527/wjn.v5.i6.547

\section{INTRODUCTION}

Antibodies directed against neutrophil cytoplasmic antigens were first described in patients with pauci-immune glomerulonephritis in $1982^{[1]}$. Antineutrophil cytoplasmic antibodies (ANCA) are associated with cases of small vessel vasculitis in granulomatosis with polyangiitis (Wegener's), microscopic polyangiitis, Churg-Strauss syndrome, "renal-limited" rapidly progressive glomerular nephritis (RPGN), and certain drug-induced vasculitis syndromes ${ }^{[2]}$. In these conditions, ANCA consistently have specificities for either PR3 or MPO, but almost never for both. We present a case of crescentic allograft glomerular nephritis after sofosbuvir therapy.

Sofosbuvir is a non-structural protein 5B RNA-dependent RNA polymerase inhibitor indicated for the treatment of chronic hepatitis $\mathrm{C}$ virus (HCV) infection as part of a combination antiviral treatment regimen ${ }^{[3]}$. Sofosbuvir's efficacy has been established in subjects with HCV genotype 1, 2, 3 or 4 infections, including those with hepatocellular carcinoma meeting Milan criteria (awaiting liver transplantation) and those with HCV and human immunodeficiency virus-1 co-infection ${ }^{[3]}$. The most common adverse reactions reported in clinical trials are that of fatigue, headache, nausea, insomnia, and anemia. Less common adverse reactions include pancytopenia and severe depression ${ }^{[3]}$. Here, we report the first case of ANCA vasculitis and RPGN following sofosbuvir administration in a kidney transplant recipient.

\section{CASE REPORT}

Our patient is a middle aged gentleman with endstage renal disease. The cause of his kidney failure was thought to be secondary to long-standing hypertension. He also had chronic HCV infection (treatment naïve) due to remote history of unprotected sexual activities. He underwent a living unrelated donor kidney transplant through our paired exchange program in June 2013. The patient received one dose of alemtuzumab (30 $\mathrm{mg}$ ) induction, and tacrolimus and mycophenolic acid maintenance without steroid. His serum creatinine ( $\mathrm{sCr}$ ) nadir was $1.4 \mathrm{mg} / \mathrm{dL} 1 \mathrm{wk}$ after transplant. Twelve weeks post-transplant, sCr was elevated to $2.0 \mathrm{mg} / \mathrm{dL}$. A kidney biopsy was performed. There was acute tubular necrosis and tubular isometric vacuolization. Tacrolimus renal toxicity was suspected, and it was replaced with cyclosporine. Subsequently, his sCr stabilized at $1.6 \mathrm{mg} / \mathrm{dL}$.

The patient had HCV genotype $1 \mathrm{a}$ infection with a viral load of $937000 \mathrm{IU} / \mathrm{mL}$ prior to transplantation. Liver function tests were normal and liver biopsy revealed stage 0 fibrosis. Thirty-two weeks after kidney transplantation, elevated liver enzymes were noted:
AST $47 \mathrm{U} / \mathrm{L}$ (0-35 U/L) and ALT $63 \mathrm{U} / \mathrm{L}$ (0-55U/L). Liver biopsy revealed chronic hepatitis $C$ changes and early focal bridging fibrosis. At week 40 after transplant, he was started with combination of ribavirin $(400 \mathrm{mg} / \mathrm{d})$ and sofosbuvir ( $400 \mathrm{mg} / \mathrm{d}$ ). Between 6 to $10 \mathrm{wk}$ of HCV treatment, he developed severe anemia that required blood transfusion for several times, despite of high dose of erythropoietin treatment. At 12 wk of HCV treatment, the $\mathrm{sCr}$ increased to $3.7 \mathrm{mg} / \mathrm{dL}$. Urine analysis had 30 $\mathrm{mg} / \mathrm{dL}$ of protein and 131 red blood cells/high powered field (RBCs/HPF), and spot urine protein-to-creatinine ratio was 0.6 . An allograft biopsy showed the presence of thrombotic microangiopathy. The viral load assays by PCR for HCV, cytomegalovirus, Epstein-Barr virus, and BK polyoma were all negative. Microbacterial cultures and drug screens were all negative. The patient had no detectable donor-specific antibodies. At this time, sofosbuvir, ribavirin, and cyclosporine were discontinued. He was started on prednisone $10 \mathrm{mg} / \mathrm{d}$ and continued on mycophenolic acid. His sCr stabilized at $2.4 \mathrm{mg} / \mathrm{dL}$.

Our patient suddenly developed hemoptysis and was admitted to an outside hospital at $57 \mathrm{wk}$ after transplant (17 wk since HCV treatment). A high resolution chest tomography of chest found bilateral peri-hilar ground glass opacities. A bronchoalveolar lavage with biopsy was performed and it revealed hemosiderin-laden macrophages and few acute and chronic inflammatory cells with focal mild interstitial fibrosis. He was empirically treated with amoxicillin for $2 \mathrm{wk}$ and hemoptysis resolved at $1 \mathrm{wk}$ of this treatment.

About 70 wk after transplant (30 wk after initiation of sofosbuvir and ribavirin treatment), he returned to transplant clinic with a $\mathrm{sCr}$ of $4.3 \mathrm{mg} / \mathrm{dL}$ and urine protein-to-creatinine ratio of 5 . Urine analysis showed more than $500 \mathrm{mg} / \mathrm{dL}$ of protein, $70 \mathrm{RBCs} / \mathrm{HPF}$. A third allograft kidney biopsy was performed and showed cellular crescents in glomeruli with pauci-immune immunoflourescent staining. Peritubular capillaries were negative for C4d staining. Electron microscopy showed normal glomerular basement membrane thickness, without electron dense deposits. A p-ANCA titer was positive at 1:320 dilution and myeloperoxidase antibody was > $100 \mathrm{U} / \mathrm{mL}$. Other tests, including c-ANCA, ANA profile, donor-specific antibodies, HCV viral load, rheumatoid factor, cryoglobulin and drug screens were all negative. Complement factors 3 and 4 were normal. The patient was diagnosed with perinuclear ANCA ( $p-A N C A$ ) associated crescentic glomerulonephritis in the transplanted allograft.

Our patient was initially treated with methyl prednisolone $500 \mathrm{mg}$ IV daily for 3 doses, then prednisone $60 \mathrm{mg}$ daily as well as cyclophosphamide $200 \mathrm{mg}$ daily. However, his renal function continued deterioration with $\mathrm{sCr}$ of $6.4 \mathrm{mg} / \mathrm{dL}$ after $1 \mathrm{wk}$ of this combination therapy. Therefore, daily plasmapheresis was added for a total of 7 treatments. His renal function continued to decline and hemodialysis was started shortly. The dose of cyclophosphamide was reduced as he developed neutropenia and painful stomatitis 2 wk later. A course 
of rituximab (750 mg weekly for 4 doses) was added. Unfortunately, he remained dialysis-dependent despite of our comprehensive efforts in treating his ANCA associated RPGN.

\section{DISCUSSION}

Our patient had a complicated course after kidney transplant with 3 significant events, for which kidney biopsies found 3 different pathologies. We believe these events may not be pathophysiologically related. The first episode of graft dysfunction at 12 wk post-transplant was consistent with typical tubular toxicity of tacrolimus. After the initiation of sofosbuvir and ribavirin therapy for HCV, he experienced the common side effect of severe anemia from this therapy ${ }^{[4]}$. Later, the worsening renal function with biopsy-confirmed thrombotic microangiopathy led us to stop his HCV treatment, although the concurrent cyclosporine was implicated as the likely cause. Obviously, we cannot determine which one of these 3 drugs (sofosbuvir, ribavirin or cyclosporine) was responsible for the development of thrombotic microangiopathy. The most significant and interesting event was the diagnosis of ANCA-associated crescentic glomerulonephritis $30 \mathrm{wk}$ after the initiation of sofosbuvir and ribavirin therapy. This was preceded with acute pulmonary hemorrhage when he was admitted to an outside facility. It is possible that our patient might have had a pulmonary involvement of ANCA vasculitis that was not diagnosed at that time.

To induce remission of new-onset organ-threatening or life-threatening ANCA-vasculitis, the combination of high dose of steroids with either cyclophosphamide or rituximab is indicated ${ }^{[5]}$. In addition, plasma exchange is also suggested for patients suffered from severe alveolar hemorrhage or RPGN with $\mathrm{sCr}$ level of $>5.7 \mathrm{mg} / \mathrm{dL}^{[5]}$. Our patient was initially treated with pulse steroids and cyclophosphamide. However, his renal function continued deterioration and a course of plasmapheresis were then added into his treatment. Due to the severe side effects of neutropenia and painful stomatitis, we reduced the dose of cyclophosphamide to half, but added rituximab with the hope to rescue his renal function. Unfortunately, he remained dialysis-dependent despite of our comprehensive efforts in treating his RPGN.

ANCA vasculitis has been reported after administration of propylthiouracil, hydralazine, cocaine, levimasole, allopurinol, penicillamine and possibly other drugs ${ }^{[2,6-8]}$. None of these medications were used and all drug screening tests were negative in our case. However, our patient was treated with sofosbuvir and ribavirin for his HCV infection before p-ANCA vasculitis developed. This suggests sofosbuvir and/or ribavirin as the possible cause. Ribavirin was first approved by Food and Drug Administration (FDA) on June 3, 1998 for HCV combination treatment. To our knowledge, there is no reported case of ANCA vasculitis associated with ribavirin yet in literature. Sofosbuvir was approved by FDA on December 6, 2013 for HCV treatment. As a new agent on the market, we suspect sofosbuvir as the possible cause of ANCA vasculitis in our patient. Also, this case is particularly interesting in that $\mathrm{p}$-ANCA vasculitis was present in the transplanted kidney as a pauci-immune crescentic glomerulonephritis. All previously reported cases of drug-associated ANCA glomerulonephritis were in native kidneys. Therefore, our case also represents the first case of drug-associated ANCA vasculitis in a transplanted kidney.

Sofosbuvir is part of a very effective and contemporary therapy for HCV infection. There will be increasing number of patients worldwide treated with this regimen or similar in the coming years. We wish our case provides a timely alert. Further drug monitoring is necessary to elucidate the degree of association and possible causal effect of sofosbuvir and p-ANCA vasculitis.

\section{COMMENTS}

\section{Case characteristics}

A middle aged gentleman developed hemoptysis 57 wk after a living unrelated donor kidney transplant, then acute renal injury.

\section{Clinical diagnosis}

Active urine sediments with hematuria and proteinuria.

\section{Clinical diagnosis}

Acute allograft rejection, BK virus nephropathy, cytomegalovirus infection, de novo nephritis

\section{Laboratory diagnosis}

Plasma perinuclear antineutrophil cytoplasmic antibodies ( $p$-ANCA) titer was positive at 1:320 dilution and myeloperoxidase antibody was $>100 \mathrm{U} / \mathrm{mL}$

\section{Pathological diagnosis}

Kidney biopsy showed cellular crescents in glomeruli with pauci-immune immunoflourescent staining.

\section{Treatment}

Initially treated with pulse steroids and cyclophosphamide, then plasmapheresis and rituximab were added.

\section{Related reports}

Several drugs have been reported to be associated with ANCA glomerulonephritis, and all of them were in native kidneys. This case suggests sofosbuvir as a new cause of ANCA vasculitis. It also represents the first case of possible drug-associated ANCA vasculitis in a transplanted kidney.

\section{Term explanation}

Drug-associated ANCA vasculitis not only occurs in native kidneys, it may also attack a transplanted kidney.

\section{Experiences and lessons}

Future drug monitoring is necessary to elucidate the degree of association and possible causal effect of sofosbuvir and p-ANCA vasculitis, including the kidney transplant recipients.

\section{Peer-review}

This is a well written paper of interest to readership of the journal.

\section{REFERENCES}

1 Davies DJ, Moran JE, Niall JF, Ryan GB. Segmental necrotising glomerulonephritis with antineutrophil antibody: possible arbovirus 
aetiology? Br Med J (Clin Res Ed) 1982; 285: 606 [PMID: 6297657 DOI: $10.1136 / \mathrm{bmj} .285 .6342 .606]$

2 Hogan JJ, Markowitz GS, Radhakrishnan J. Drug-induced glomerular disease: immune-mediated injury. Clin $\mathrm{J} \mathrm{Am} \mathrm{Soc}$ Nephrol 2015; 10: 1300-1310 [PMID: 26092827 DOI: 10.2215/ CJN.01910215]

3 Sovaldi: Gilead Sciences. [accessed 2015 Mar 31]. Available from: URL: http://www.gilead.com/ /media/Files/pdfs/medicines/liverdisease/sovaldi/sovaldi_pi.pdf

4 Kelleher TB, Afdhal NH. Management of the side effects of peg-interferon and ribavirin used for treatment of chronic hepatitis C virus infection. UpToDate 2015. [accessed 2015 May 14]. Available from: URL: http://www.uptodate.com/ contents/management-of-the-side-effects-of-peginterferonand-ribavirin-used-for-treatment-of-chronic-hepatitis-c-virusinfection? source $=$ machineLearning\&search=ribavirin anemia\&sele ctedTitle $=1 \sim 150$ \$ionRank $=1$ \&anchor $=\mathrm{H} 2 \# \mathrm{H} 2$

5 Yates M, Watts RA, Bajema IM, Cid MC, Crestani B, Hauser T,
Hellmich B, Holle JU, Laudien M, Little MA, Luqmani RA, Mahr A, Merkel PA, Mills J, Mooney J, Segelmark M, Tesar V, Westman K, Vaglio A, Yalçındağ N, Jayne DR, Mukhtyar C. EULAR/ERAEDTA recommendations for the management of ANCA-associated vasculitis. Ann Rheum Dis 2016; 75: 1583-1594 [PMID: 27338776 DOI: 10.1136/annrheumdis-2016-209133]

6 Ito-Ihara T, Ono T, Nogaki F, Suyama K, Tanaka M, Yonemoto S, Fukatsu A, Kita T, Suzuki K, Muso E. Clinical efficacy of intravenous immunoglobulin for patients with MPO-ANCAassociated rapidly progressive glomerulonephritis. Nephron Clin Pract 2006; 102: c35-c42 [PMID: 16174989 DOI: 10.1159/0000 88313]

7 Espinoza LR, Perez Alamino R. Cocaine-induced vasculitis: clinical and immunological spectrum. Curr Rheumatol Rep 2012; 14: 532-538 [PMID: 22875288 DOI: 10.1007/s11926-012-0283-1]

8 Seo $\mathbf{P}$, Stone JH. The antineutrophil cytoplasmic antibody-associated vasculitides. Am J Med 2004; 117: 39-50 [PMID: 15210387 DOI: 10.1016/j.amjmed.2004.02.030]

P- Reviewer: Mahmoud KM, Nakhoul FM, Saleem M S- Editor: Gong XM L- Editor: A E- Editor: Li D 


\section{DS \\ Baishideng ${ }^{\circledR}$}

Published by Baishideng Publishing Group Inc

8226 Regency Drive, Pleasanton, CA 94588, USA

Telephone: +1-925-223-8242

Fax: +1-925-223-8243

E-mail: bpgoffice@wignet.com

Help Desk: http://www.wjgnet.com/esps/helpdesk.aspx

http://www.wjgnet.com

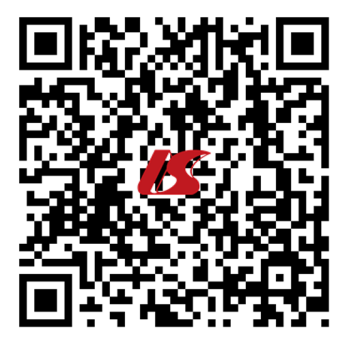

